\title{
Computational environment HYDRO-PATH as a flexible tool for operational rainfall-runoff model design
}

\author{
Tamara Tokarczyk, Wiwiana Szalińska, Andrzej Tiukało \\ Institute of Meteorology and Water Management - National Research Institute, Podleśna 61, 01-673 Warsaw, Poland, \\ e-mail: tamara.tokarczyk@imgw.pl,wiwiana.szalinska@imgw.pl,andrzej.tiukalo@imgw.pl
}

\author{
Jan Jełowicki \\ Wroctaw University of Environmental and Life Sciences, Faculty of Environmental Engineering and Geodesy, Plac \\ Grunwaldzki 24, 50-363 Wroctaw, Poland, e-mail: jan.jelowicki@up.wroc.pl
}

\author{
Artur Chorążyczewski \\ Wroctaw University of Science and Technology, Institute of Computer Engineering, Control and Robotics, Janiszews- \\ kiego 11-17, 50-372 Wrockaw, Poland, e-mail: artur.chorazyczewski@pwr.edu.pl
}

\begin{abstract}
The overall objective of the ongoing work is to develop the computational environment HYDRO-PATH as a flexible tool for forecasting runoff from catchment areas for various hydrometeorological conditions while taking into account the information available on a real-time basis. Ensuring the model's operational reliability and reducing the uncertainty of generated forecasts is accomplished through the adjustment of both the internal structure of the model and the spatial representation of the computational grid to the physiographical, hydrological and climatological characteristics of a given basin. The research focused on the development of methods for selecting the optimal model structure and parameters by analysing the results obtained for different model structures. This is achieved through the computational environment, in which it is possible to implement different types of hydrological rainfall-runoff models. These models have a unified system of data input, parameter optimisation rules, and procedures for result generation. The developed elements of the computational environment correspond to generation potential of models with a given structure and complexity. Furthermore, within the framework of HYDRO-PATH the following components were developed: an application programming interface (API), a data assimilation module, a module for computational representation of a real object, and a module for the estimation and optimisation of model parameters. The developed computational environment was applied to prepare a version of TOPO-Flex and perform hydrological validation of the model's results. The hydrological validation was performed for selected flood events in the Bystrzyca Dusznicka subbasin of the Nysa Kłodzka River.
\end{abstract}

Keywords: rainfall-runoff model, operational application, computational environment, model development, system design

Submitted 31 August 2015, revised 29 December 2015, accepted 24 May 2016

\section{Introduction}

Simulating runoff from a catchment is still a topical subject in modern hydrology. Runoff is the result of the final transformation of catchment supply through a complex system of interrelated unit processes such as precipitation, evapotranspiration, water flow and water storage that are characterised by different spatial scales and temporal variability. The common procedure for building hydrological simulation models it to prepare the element model for each process and build an integrated system model by connecting the element models according to the basin characteristics and the scope of a model.

The proper understanding of hydrological processes is the basis for the formulation of an appropriate set of mathematical functions to describe these processes, and enables the identification of hydrological model parameters for their simulation (Chormański, Michałowski 2011). The choice of model structure that is best suited for a given purpose and scope of modelling can be based upon the analysis of a catchment>s characteristics and also on the analysis of the dynamics of the processes influencing the runoff magnitude under given conditions, as well as in the course of targeted diagnostics of the results obtained with different model structures (Brown et al. 1999; Clark et al. 2011). Generating the ensemble forecasts from many models allows for better results to be obtained in runoff hydrograph simulation than when 
seeking one best model (Butts et al. 2004; Georgakakos et al. 2004; Cloke, Pappenberger 2009; Velazquez et al. 2011; Seiller et al. 2012). This is due to the fact that using the diverse structures of a model allows one to account for different aspects of the object and its processes being modeled (Wagener et al. 2001; Wagener, McIntyre 2005). It is therefore important to seek complementary structures that will allow for the advantages of the most effective components included in various models to be combined (Perrin et al. 2001). The multi-model approach is in line with the solutions currently promoted which emphasise the need to develop a rational methodology for integrating various models, as well as objective methods for the verification and determination of the uncertainty of the results (Gan et al. 1997; Butts et al. 2004; Wagener, McIntyre 2005; Kirchner 2006; Fenicia et al. 2008a, b, 2011; Kavetski, Fenicia 2011).

The structure and parameterisation of a rainfall-runoff model also depends on the operating mode of the model. In other words, the operational working mode of the model imposes a compromise between advanced methods for the modelling of hydrological processes and the performance of the forecasting process - understood as the ease of model parameterisation, the speed of obtaining the adequate information, and the quality of the results. Conceptual models with lumped parameters are used most commonly in operational applications (Perrin et al. 2001; Todini 2006; Lastoria 2008). This is determined by simple model structure, the small amount of the input data required, as well as by the possibility of automatic parameter calibration. However, more and more attempts are being made to implement into operating systems, simplified physical models of semi-distributed parameters. In contrast, physical models with distributed parameters, due to the extent of the requirements relating to input data as well as long computation time, are not used in operational practice (Wagener, McIntyre 2005; Todini 2006). The most appropriate approach considered consists in adopting the simplest possible model structures - this enables the realisation of a given objective in an economical manner in terms of data availability, the amount of input data and calculation time (Gądek 2002).

Currently, a research project is being implemented at the IMWM-NRI which aims at the development of an effective tool for forecasting runoff from a catchment under various hydrometeorological conditions, taking into account information available in the operational mode. In pursuit of that objective, the computational environment HYDRO-PATH was designed as a flexible system for building and operating various hydrological rainfall-runoff models. The models prepared in the HYDROPATH compu- tational environment have a unified scheme for data assimilation, parameter optimisation and generation of results.

The computational environment is to enable the user to easily develop a new element model of a hydrological system, build or modify an available integrated system model, optimise the structure and parameters of a rainfall-runoff model - depending on the geophysical, meteorological and hydrological characteristics of a given catchment, provide multi-model ensembles of the runoff simulation, and forecast on real-time basis.

Achieving these objectives requires the development and preparation of advanced IT tools and decision support procedures for catchment schematisation, and the construction and operation of rainfall-runoff models with different spatial and functional complexity, which will operate in different modes: as simulation and/or operational, forecast models.

This article presents the state of play concerning the development of the HYDRO-PATH computational environment for the construction of rainfall-runoff models with a given structure, and the preliminary results of simulating runoff from a catchment.

\section{Modelling system}

Hydrological modelling of a rainfall-runoff process can be performed with the use of a system approach. The system approach defines individual system objects, the attributes of those objects, and the relationship between objects along with the following system properties (Soczyńska 1997):

- the system may consist of any number of objects,

- objects are clearly separated, but may be interdependent,

- the system provides a structured set of objects,

- the system maintains the principle of cause-and-effect, input-output,

- the overriding element of the system is its function,

- the interdependence input-output is realised in the given time period,

- the system inputs and outputs may be different in nature,

- the input can be distributed in space and time.

The HYDROPATH computational environment responds to the assumptions of a system approach for hydrological model development and creates a structural framework for building and operating rainfall-runoff models. Structural frameworks form an ordered approach for achieving a compromise between the required functionality of the model structure and the number of parameters in the model - this is identifiable with an available data set to obtain satisfactory accuracy of the results and to reduce the level of uncertainty. 


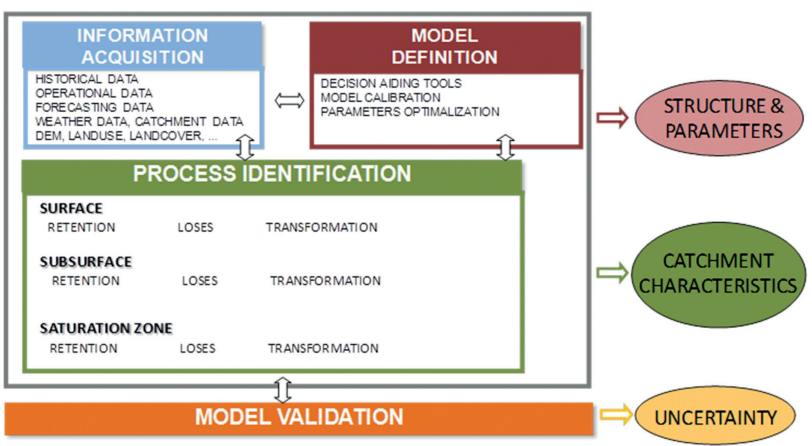

Fig. 1. Components of structural framework for building and operating rainfall-runoff models

The structural framework consists of four basic components with specific functionalities and interactions: i) information acquisition, ii) process identification, iii) model definition and iv) model validation. Within this framework each alternative model is represented as a separate object that differs in terms of the analysed process description, parameterisation and the required input data. Each integrated model can be expressed in terms of a set of objects representing element models. All objects are standardised in terms of their logical structure and method of data transfer between objects. This object-oriented approach allows for the flexible definition of new model structures or new model functionalities and operability. Flexibility is also important in terms of the dynamic nature of the system in which objects are arranged in precisely-defined dependencies that can vary over time.

In order to ensure the functionality of the system it is necessary to implement for each component at least one conversion function between a set of input and output data. In turn, the modular structure provides for the possible introduction of new system objects, as well as the modification and expansion of the existing ones, which make up the individual components. This allows for the use of different internal model structures of the transformation of rainfall into runoff, ranging from simple correlation models to the physical models with distributed parameters and the use of different structures for catchments with different characteristics. The basic products intended to be obtained with the use of developed system are: 1) the structure and parameters of the rainfall-runoff model, 2) catchment characteristics, and 3) evaluation of uncertainty (Fig. 1).

\section{HYDRO-PATH computational environment}

HYDRO-PATH computational environment is a system of IT tools for building and operating rainfall-runoff models with different spatial and functional complexity. The process of model building includes model structure identification and deployment, depending on the scope and purpose of modelling, available data, the unit process included, and catchment characteristics. The operation of rainfall-runoff models depends on a selected operating mode and the required accuracy of results. The computational environment allows for the development and application of integrated rainfall-runoff models or element models of a unit process which, when combined, have the functionality of the integrated models. The resulting product is a calculation template customised for a particular purpose and scope of operation, which provides an assessment and forecast of runoff from a catchment area for a specific uncertainty range (Fig. 2).

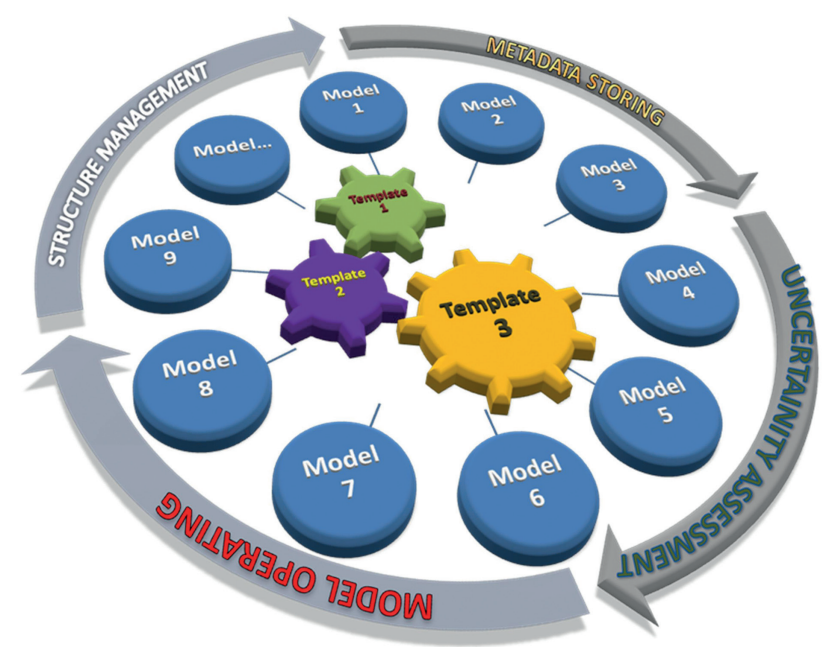

Fig. 2. Schematic diagram of the HYDROPATH computational environment for building and operating hydrological rainfallrunoff models

The computational environment forms a distributed system that operates on the population of rainfall-runoff models with different characteristics. An important feature of the operation of a computational environment is constituted by the reconfigurability of a given calculating template in terms of model structure and its parameters, depending on changes concerning the modelling purpose and scope, operating mode and available data.

Management of model structure - this aims at finding the optimal model solution (structure and parameters) for a given configuration of catchment characteristics. The structure of a rainfall-runoff model, with its impact on the quality of results, as well as methods for optimisations that structure to fit the environment characteristics of a catchment area, are still a current challenge of great importance in terms of application (Gan et al. 1997; Butts et al. 2004; Wagener, McIntyre 2005; Kirchner 2006; Fenicia et al. 2008a, b, 2011; Kavetski, Fenicia 2011; Chou 2012). The choice of model structure that is best suited for a given purpose and scope of modelling should include analysis 
of the characteristics of a catchment and the nature and dynamics of the processes influencing runoff magnitude under particular conditions (Brown et al. 1999; Clark et al. 2011). One such tool for structure management is a decision tree containing a sorted set of rules that guide and lead to specific solution paths and the selection of specific modules of a model. The development of decision-aiding tools for the selection of flood forecasting models is in line with the WMO Flood Forecasting Initiative. An example of a decision tree made up of three types of blocks: query (yellow), model component (grey) and required data (green) is shown in Fig. 3

The composition of the decision tree is oriented from the gauge (or location) for which the forecast is to be developed, to the basin upstream. As a result, detailing of the model structure is obtained by compositions and integra- tions of individual functional components. The decision scheme indicated above is executed at the stage when a model is prepared for implementation into operational work. The decision tree is a dynamic adaptive approach, implemented as a function of the acquisition of available information on the current status of the object modelled, available data and available model solutions.

Metadata repository - completion of the refinement of the model structure for a particular forecasting purpose, catchment characteristics and the measurement data available under the analysed conditions is followed by the phase of calibration and validation of the selected model structure. This phase aims at the identification of the parameters for a specified model structure. The calibration and validation phase is part of the evaluation of the quality of selected

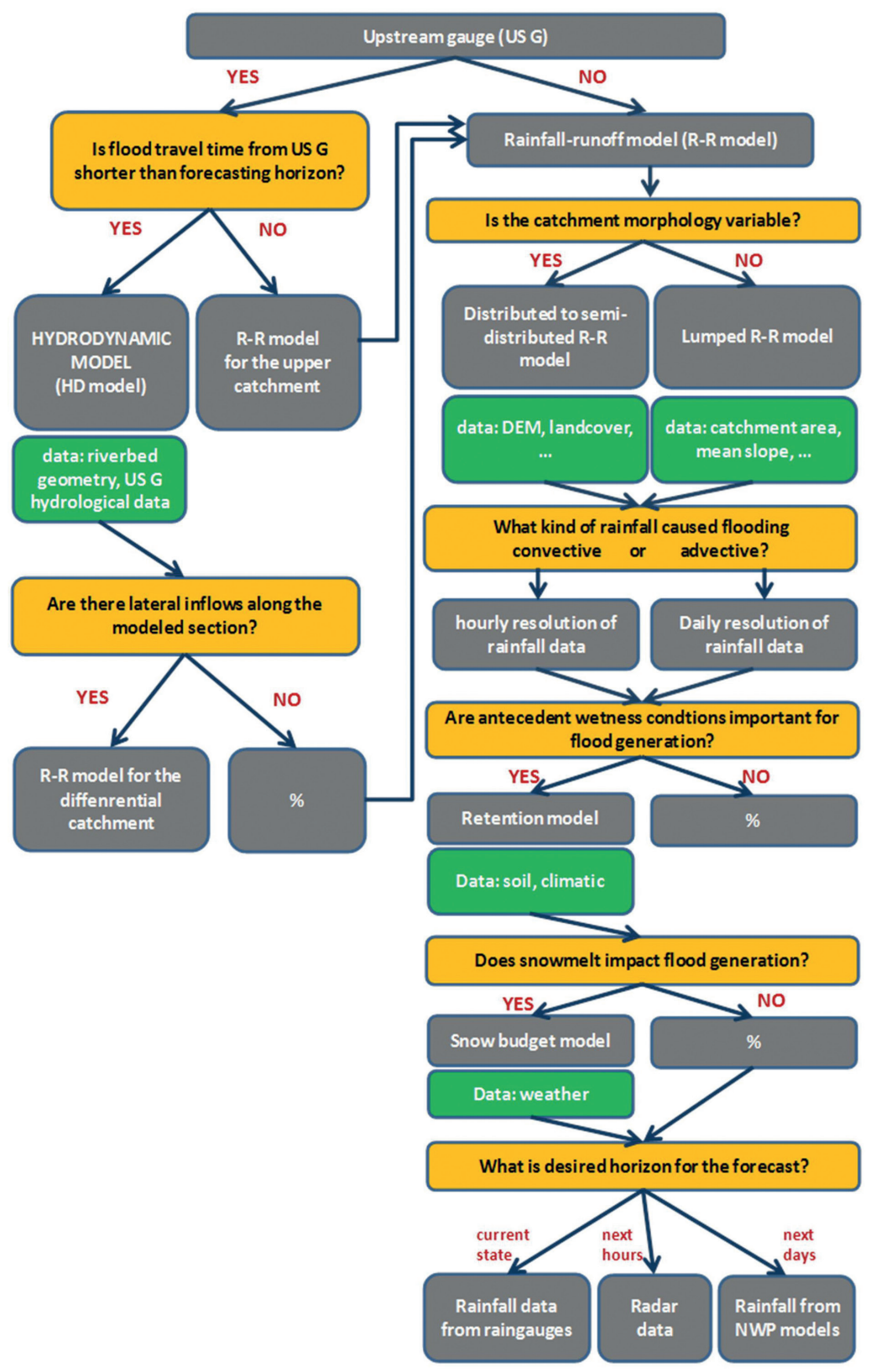

Fig. 3. Schematic decision tree for selection of flood forecasting model (based on the WMO Flood Forecasting Initiative) 
structures (Gan et al. 1997; Son, Sivapalan 2007; Gupta et al. 2008; Pushpalatha et al. 2011). The ability of the model to reproduce the observed runoff is tested with respect to the specified quality and quantity of data. It is planned that the multi-criteria methods for evaluation of the model's results will be applied to validate the performance of individual model components in mimicking unit processes (Yilmaz et al. 2008). Multi-criteria evaluation is a basis for conducting the process of model optimisation that tackles, separately, different components of a hydrograph: rising limb, peak segment or falling limb (Gupta et al. 1998; Shamir et al. 2005; Westerberg et al. 2011).

Identification of the structure and parameters of the model is followed by the model and available information on modeled object being saved in a dedicated metadata repository. The metadata include the following elements, which together form the template model: (i) the catchment morphometric parameters, (ii) climatic and hydrological conditions of the catchment area; (iii) the model structure, (iv) the parameters of the processes, (v) the model parameters, (vi) evaluation criteria, (vii) the model quality. The construction of the repository, in the form of a relational database, allows for the information to be grouped on a given template as a set of records of a unified internal structure, as well as of the relationships that occur between the data.

Evaluation of uncertainty - the uncertainty in the results obtained from the model is primarily due to random or systematic errors of the model's input data and the data used for model calibration (Thyer et al. 2009), as well as the process of parameter optimisation and selection of the optimal set of parameters, and also arise from the structure of the model adopted (Wagener et al. 2003). Reduction of the uncertainty due to the quality of the input data is realised in the course of obtaining the information from alternative measurement methods and through appropriate data fusion to obtain the best product (Vaze et al. 2011). For rainfall-runoff models, this mainly concerns the rainfall information that can be acquired from ground stations, as well as radar and satellite data (Szturc et al. 2014). Reduction of the uncertainty resulting from the adopted model structure will be achieved through the generation of ensemble forecasts using alternative model structures and parameters.

Operating mode - individual elements of the computing environment are created, developed and operated in different modes. In distinguishing between simulation, operational and forecasting modes, the functioning of a rainfallrunoff model is related with the execution of the following tasks:
- simulation mode - work with historical data, model structure management, metadata repository construction, model calibration and validation, assessment of model uncertainty, selection of for to building ensemble forecasts;

- operational mode - real-time model template operation, measurement data assimilation, online assessment of the uncertainty of the results obtained from the model;

- forecasting mode - real-time model template operation, measurement and assimilation of data from weather forecast models, ongoing assessment of the uncertainty and forecasting of the uncertainty of the assessment of current and predicted values, updating the data.

\subsection{Functionality of the computational environment}

The computational environment was designed to satisfy the following basic requirements: (1) application versatility (2) iterative development, (3) modularity, (4) openness.

Application versatility - this can be satisfied by providing a standardised method for defining a model structure, parameters and data transfer, both within and outside a model. This allows for the existing hydrological models to be imitated, or for the formulation of new ones. The solution being sought is to provide a tool for building an integrated model, wherein the unit processes are described through separate operators. The operator functions may be of various levels of complexity and depending on modelling needs and data availability.

This will facilitate the comparative analysis of the outcomes from different methods of modelling the same object (catchment) and build an ensemble of forecasts.

The iterative development refers to the incremental process of model building based on the results gained from the model exploitation. Learning comes from both the development and use of the model for a particular catchment environment and particular hydrometeorological conditions. Catchment environment characteristics are used in the process of finding the optimal spatial resolution of the catchment model. In the first step, the model with lumped parameters is analysed, which, in the case of unsatisfactory results, it is subjected to a delineation according to the criterion relating to the DRPs, which have various degrees of detail. Accordingly, different model structures can be applied for the same catchment but for different meteorological conditions. Following the implementation of the simplified model construction after the verification of the model results, some new model elements can be added. 
Modularity consists of the interaction between subsystems pursuing distinct, well-defined tasks. For this purpose, each function block of computational environment must be expressed as a function or a function class. The internal interfaces of the system use structured data types, for example vectors and objects, while the external interfaces are implemented using files. This provides flexibility in configuring the model structure within the different operating modes. For this case, it is permitted to construct a model (which is composed of various models, each of which, working under various hydrometeorological conditions, is taken into account) and a function enabling dynamic switching between different models.

The openness of a computational environment is implemented at two levels: at the level of implementation and at the level of use. At the level of implementation it is the availability of source code, definitions of interfaces released to the public, and access to full software documentation. At the level of use it is, among others things, a description of the catchment models in plain text (in XML notation) - the user decides about the manner and extent of identification of the model and its parameters, as well as about the ability to import data from various sources.

The functionality that has been achieved so far of the computational environment includes support for the process of building and operating a catchment model through multi-level iterations carried out within the following cycle (Fig. 4):

- carrying out a dedicated diagnostic scheme of the catchment to be modelled using GIS techniques in order to divide the catchment area into the subareas of a specified dominant runoff process (DRP);

- for each type of subarea, selection of a rainfall-runoff model structure adjusted to the identified processes af-

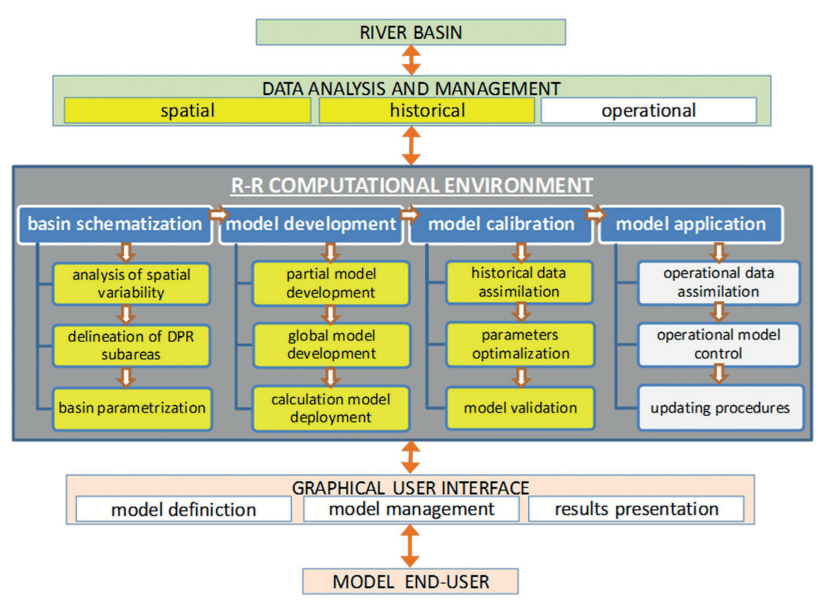

Fig. 4. Schematic diagram of the HYDRO-PATH computational environment; the yellow boxes denote the modules that have been implemented at the current stage of system development fecting the transformation of rainfall into the runoff;

- the description of different types of subareas with their own individually parameterised rainfall-runoff models (development of partial models);

- the schematisation of interaction between the areas adjacent to DRPs, at the level of individual layers: the surface, subsurface and groundwater;

- the creation of an integrated (global) model as a set of equations describing the catchment;

- a solution to the system of equations that build an integrated model for a given time period - in order to form a calculation model.

\subsection{Structure of the rainfall-runoff models}

On one hand, a rainfall-runoff model structure should be of modular and open construction due to rapidly changing IT technologies. On the other hand, it should be a compromise between advanced methods of hydrological modelling and the efficacy of the forecasting process.

Hydrological rainfall-runoff models take the form of balance equations systems. They are generally formulated using the systems of ordinary differential equations. The individual equations of such systems express the principle of mass conservation in a conceptually separated catchment part that exchanges mass with other similar components. Quantitative mass transfer characteristics are determined using many functions of flow rate, depending on the specific parameters. Each delineated subarea corresponding to a particular DRP of a catchment is described by a set of reservoirs connected by the equations describing the water flow. Each reservoir exchanges water through one of four mechanisms - inflow/rainfall, evaporation, infiltration, runoff (Fig. 5).

Unrestricted connections between reservoirs allows for the creation of a wide range of catchment models. The description language of model structures, developed for the needs of computational environment, represents the standardised method for model structure description and allows for a formal definition of hydrological models. It is used to define the properties of individual model elements, such as reservoir, source, sink, junction, diversion or functions describing the exchange of water in a uniform manner at the level of interpreted data. This creates the potential of the computational environment to produce rainfall-runoff models in any configuration and complexity as well as to combine developed models according to adopted rules. The quantity, characteristics and configuration of the model elements will be different depending on the model class and the type of physical phenomena taken into account. The description language allows for the de- 


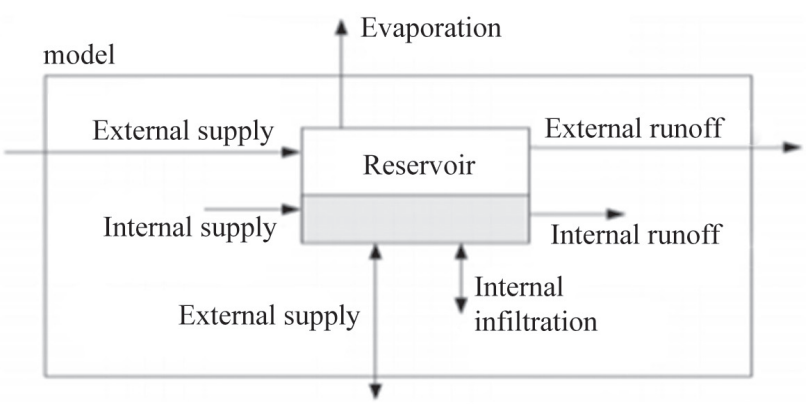

Fig. 5. Model of reservoir and water exchange through inflow/ rainfall, evaporation, infiltration, runoff

clarative expression of relationships between the objects, based on a set of elementary functions. The built-in language parser system allows for the transfer of the model defined by a user into a computer, which can run software and provide different forms of presentation.

Key components of catchment model description language include the basic library and catchment components library.

Higher levels of management of data structures available in the computing environment allow for the construction of hydrological models that constitute the system of dependent objects. The component library contains a collection of structures' catchment hierarchical-objects designed to represent the components of the hydrological cycle in a rainfall-runoff model. The developed prototypes are of objects for several basic types of components, and subbasins. These are mainly power nodes, representing rainfall and evapotranspiration, reservoirs in several configurations, sinks, and also functions of the mass exchange between these objects, such as junctions, diversions, routing.

Consequently, the software tool for constructing hydrological rainfall-runoff models, implemented in the computational environment, supports the following data structure:

- Modules: these represent objects between which the data is exchanged. Most modules have their own state vector. A module may have any number of links to other modules that control the manner of mass transfer and thus the properties of the catchment model. Examples of modules:

- Reservoir - basic type of module, representing the storage of mass in the form of a reservoir with lumped parameters.

- Source - they provide a connection between the modules with defined state (mainly reservoirs) and external data. Individual subtypes of feeding modules can set the values from various data sources (of different resolutions and structure).

- Modules of this type are stateless (i.e. do not represent any state variables in the catchment model).
They may have their own parameters and registered functions.

- Composite modules - a type of module that allows for the mapping of objects of diverse internal structure, including modules and links. An example of such an object is an elementary catchment. Composite objects consist of lower-level modules (which may also be composite) and the links binding them. Like other objects, composite modules can also record user-defined functions. They are available during the setting up and operation of the slave devices. The parameters passed to a composite module are propagated to the sub-modules, links and functions.

- Connections, or links (i.e. junctions, diversions), are objects representing the relationships between components of the equations of the model-specific modules. The links describe components of the mass balance between the modules. Each link has its parent module, and a list of its dependant modules. A link includes a calculation object (function), the evaluation of which calculates the appropriate component of the flow between modules. The link parameters vector allows for the setting of the numerical values characterising the computational function adopted. The links use the model state vector as an argument to define their function of flow. Links are also equipped with an interface that allows the consideration of the relations modelled through it in the model's global system of equations. The object-oriented concept of links with configurable computing functions allows for the construction of a model catchment according to detailed needs (Clark et al. 2008).

Models: A model is an extension of a composite type module, equipped with an interface to build its own state vector. The models also have tools for the serialisation and deserialisation of its own structure, set of parameters and state vector. The model type object includes a description of its components and the relationships between them. This allows for the mapping of catchment area components corresponding to the desired configuration (e.g. known from the literature) of a hydrological model. The file format uses XML notation, and its syntax rules are described using XML Schema. The contents of the modules described in the files are processed into a data structure by a suitable translator.

A catchment model template is an important configuration structure. This is an XML document, or part of such a document, containing a formal description of adopted models of elementary catchments. The template contains 
a complete description of the model modules and interdependence among them (including the names of the required attributes and numeric parameters). Ultimately, in a computational environment the templates reflecting the selected types of hydrological models will be implemented. It will also be possible to complement the template set with templates prepared by users.

\subsection{Operation of rainfall-runoff models}

Within the computational environment, the definition of rainfall-runoff model structure and the construction of a calculation model (model equations preparation) are separated from the process of solving the set of equations. The latter is done within the framework of a simulation module supplied with the procedures for solving the system of equations governing the mass balance. The function of this module is to link the structures reflecting the components of the catchment area with their states, treated as the function of time combined with the possibility of assessing the changes in this vector of states as time passes, according to an input vector.

The simulation module engages numerical methods dedicated to solving systems of ordinary differential equations (intended to also be partial) and systems of differential-algebraic equations (DAE); the control of the integration step of these equations; and the binding behaviour of model input data streams delivered in the form of time series. The integration step is chosen automatically for the entire model, taking into account the existing non-linearity of flows.

Within the computational environment, different technologies to solve a system of equations are planned to be implemented. So far, assays are solved based on the classic Runge-Kutta fourth-order methods (eg. Press et al. 2007).

The next stage of model operation is the estimation of model parameters to ensure the optimal fitting of the responses (runoff from the catchment) to the observation. Changes in a state vector over time are determined by linking the model conservation equations to the input data streams (rainfall and evapotranspiration) supplied in the form of time series. The time series describing the intensity of rainfall and evapotranspiration are obtained in the form of raster maps with a fixed pixel size and a temporal resolution. The module for the description of the catchment geometry can make a summation and an averaging of input values in the areas required by the structure of the model. Such series, stored in text files, are assigned as data sources for source type modules. They are read automatically during the process of solving the equations of the model. The import of the input data assumes the assimilation of the model's input data: raster data, point data and vector data.

Currently, the Rain GRS (Ground-Radar-Satellite) meteorological data, as a product from combined three sources, are provided in the form of raster data that represent the best estimation obtained by using information from various sources (Szturc et al. 2014). Simultaneously with the rainfall field, the quality indicator (QI) is generated, defining its quality on a continuous $0-1$ scale (data completely wrong - data ideal). Data points represent the observed flow rates for a given gauge. Vector data represent the contours of the separate DRP areas. As a result of parsing, time series of meteorological variables mean values for the area are received. The module is equipped with the implemented internal representation of the model grid using a quad tree scheme that allows the recursive division of space into sub-blocks and by that means the reproduction of any shape at the required level of accuracy (Fig. 6).

Another issue relating to the process of operating the models is the model parameter estimation (calibration model). An optimisation procedure has been developed which estimates the optimal parameter values for a given set of pairs (input, output) using methods of multidimensional optimisation: SQP square approximation (Nocedal, Wright 2006) and stochastic growth (Bäck, Schwefel 1993). A user can select a set of parameters to be optimised and the range of values of a given parameter. To assess the

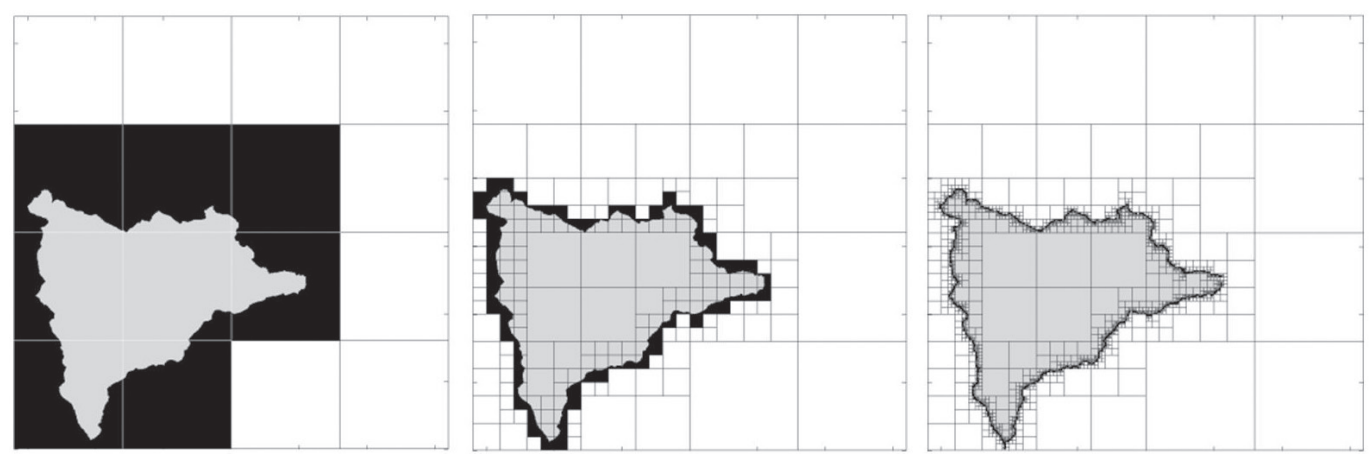

Fig. 6. Internal representation of the elementary catchment contours using the technique of quad trees at selected levels of representation: a) level 2, b) level 5, c) level 8 
compatibility of the hydrographs measured and resulting from simulations, the measures of quality are used - first of all root mean square error RMSE (Anderson, Woessner 1992) and Nash-Sutcliffe (Nash, Sutcliffe 1970), as well as other measures dedicated to assessing an error of specific runoff characteristics such as wave volume or peak discharge.

\section{Rainfall-runoff model of the Bystrzyca Dusznicka catchment}

At this stage of system development, decision-aiding tools for model structure selection that are to be provided through the Graphical User Interface (GUI) are still under construction. The operability of such tools depends on the range of available unit or integrated models to be investigated in terms of their adequacy to represent catchment characteristics, forecast demands or input data required. Therefore initial efforts were made to build up a database of pre-defined rainfall-runoff model structures developed within the HYDRO-PATH computational environment.

So far the computational environment has been used to build the rainfall-runoff models: TOPMODEL with lumped parameters, and TOPO-Flex, with semi-distributed parameters (Gao et al. 2014) for the Bystrzyca Dusznicka catchment. Both model structures are designed to take into account topographical information in runoff estimation. This is crucial in the case of mountainous catchments like Bystrzyca Dusznicka. The results of the simulation model TOPMODEL are presented in the publication Szalińska et al. 2014. The paper presents the preliminary results obtained for the TOPO-flex model configuration.

\subsection{Description of the Bystrzyca Dusznicka catchment}

The annual rainfall course in the catchment of Bystrzyca Dusznicka has continental, maximum rainfall occuring in July, with its minimum in February. Precipitation in the summer (June-August) is from $33 \%$ to $44 \%$ of total annual precipitation in the catchment. The average share of the spring and autumn quarters in total annual rainfall is respectively $23 \%$ and $21 \%$. The mean annual temperature in the basin is about $7.5^{\circ} \mathrm{C}$. The flow values characteristic for the multi-year period 1971-2010 in the Bystrzyca Dusznicka catchment are presented in Table. 1.

The outflow regime is as follows: the highest low flow is observed in the period March-April; the lowest low flow occurs between May and October. The average outflow has two distinct peaks: spring (after the thaw) and summer (July).

The possibility of collecting water is found mainly in subsurface layer rock rubble and the weathering of rock
Table 1. Flow rate characteristics for the years 1971-2010 in the Bystrzyca Dusznicka catchment area

\begin{tabular}{|c|c|c|c|c|c|}
\hline $\begin{array}{c}\text { Water } \\
\text { gauge }\end{array}$ & River & $\begin{array}{c}\text { Catchment } \\
\text { area } \\
{\left[\mathrm{km}^{2}\right]}\end{array}$ & $\begin{array}{c}\text { average } \\
\text { low } \\
\text { flow } \\
{\left[\mathrm{m}^{3} / \mathrm{s}\right]}\end{array}$ & $\begin{array}{c}\text { average } \\
\text { mean } \\
\text { flow } \\
{\left[\mathrm{m}^{3} / \mathrm{s}\right]}\end{array}$ & $\begin{array}{c}\text { average } \\
\text { high } \\
\text { flow } \\
{\left[\mathrm{m}^{3} / \mathrm{s}\right]}\end{array}$ \\
\hline $\begin{array}{c}\text { Szalejów } \\
\text { Dolny }\end{array}$ & $\begin{array}{c}\text { Bystrzyca } \\
\text { Dusznicka }\end{array}$ & 175,00 & 2,20 & 8,20 & 39,30 \\
\hline
\end{tabular}

and slotted zones. The rock rubble zone coverage and weathering is small and usually reaches only a few meters below the ground surface. With increasing depth, decreases in the outflow regime are as follows: the highest low flows are observed in the period March-April; the lowest low flows occur between May and October. The average outflow has two distinct peaks: spring (after the thaw) and summer (July).

\subsection{TOPO-Flex for the Bystrzyca Dusznicka catch- ment}

TOPO-flex was prepared with the use of implemented IT tools according to the diagram presented in Fig. 4. The first step involved basin schematisation in order to parameterise the analysed area.

Parameterisation of the catchment area for the purposes of building the model with semi-distributed parameters is directed at dividing the catchment into the areas with homogeneous runoff types. This approach to parameterisation of a catchment area is has currently been developed by a number of authors (Müller et al. 2009; Gharari et al. 2011, 2013; Hümann, Müller 2013; Geo et al. 2014). A key aspect of the division of the catchment according to established criteria is the choice of thresholds for particular types of area. The division was based upon a methodology using the analysis of height above nearest drainage (HAND) together with the slope of the area. Both parameters are determined on the basis of the digital terrain model (Rennó et al. 2008; Nombre et al. 2011). The areas resulting from the delineation, based on the aforementioned criteria, represent the catchment areas with homogeneous runoff types (Savenije 2010). In sloped areas with high forestation there is a balance between the process of water retention and surface flow (Savenije 2010). The dominant process of runoff formation in these areas is therefore the subsurface runoff. Terraced areas are characterised by a moderate inclination and the relatively deep location of the groundwater table. The low topographical gradient and, potentially, a large depth saturation zone are conducive to water retention by percolation. The dominant process of forming the runoff in this area is interflow. The areas including river valleys are characterised by a small 


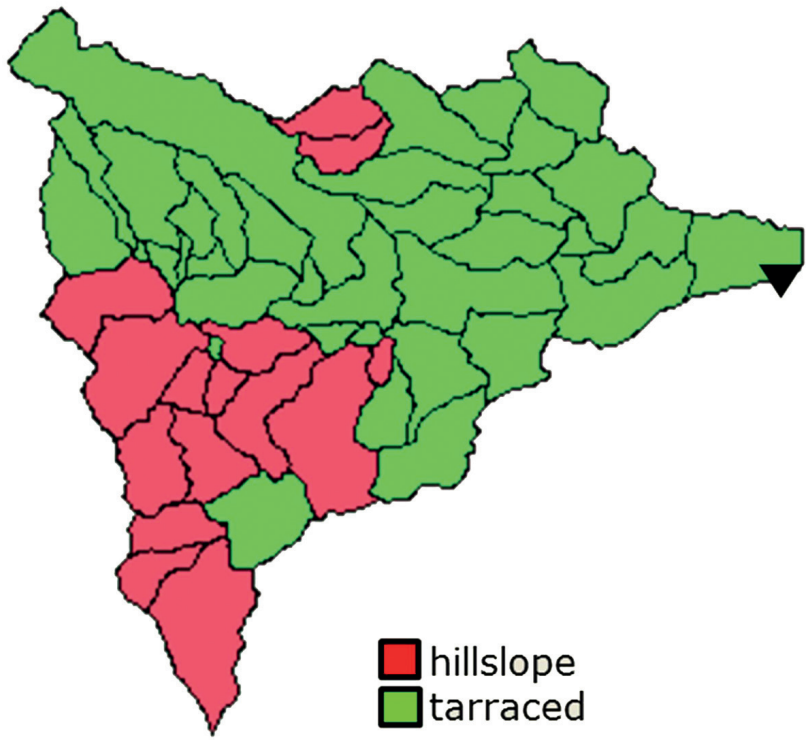

Fig. 7. Delineation of the Bystrzyca Dusznicka into DPR subareas according to HAND procedure

inclination, and a high groundwater table position. The dominant process is the surface runoff.

For the Bystrzyca Dusznicka catchment, the following thresholds have been applied: hand [m] 16.2; slope [\%] 11.6. The spatial distribution of sub-catchment (areas with a predominant runoff process) is shown in Fig. 7, where the areas marked red represent the sloped areas with a predominant subsurface runoff process, and the areas marked green show terraced areas with a predominant interflow process.

Next step was to develop a global model for the Bystrzyca Dusznicka catchment consisting of two partial models representing hillslope and terraced areas. Both partial models were parameterised separately, along with the functions representing lag times for the outflows from delineated subareas to reach the closing outlet of the analysed basin. With the use of the internal parser system, the global model was converted into a calculation model ready for calibration with the use of historical data. Optimisation of model parameters was carried out for the period of 29.04.2010 to 20.06.2010 with the use of RMSE as criteria to evaluate the quality of the agreement between observed and simulated hydrographs.

Model validation was carried out for the period of 20.07.2015 to 30.07.2015. Simulation of the flood wave obtained with the use of TOPO-Flex rainfall-runoff model within the HYDRO-PATH computational environment proved satisfactory agreement with the observed flood wave hydrogram (Fig. 8).

Model application, including operational model exploitation, is the subsequent step of operational model development. The set of IT tools to support this process are currently under construction and will be presented in a subsequent paper.

\section{Conclusions}

The HYDRO-PATH computational environment is a modelling system developed within the interactive and incremental development cycle. The basic idea behind this method is to start with a simple implementation of a subset of the system requirements and iteratively enhance the evolving versions until the full system is implemented. At each iteration, design modifications are made and new functional capabilities are added.

This allows both the development and use of the system to be taken advantage of to improve the system functionality. The first phase of developing the HYDRO-PATH

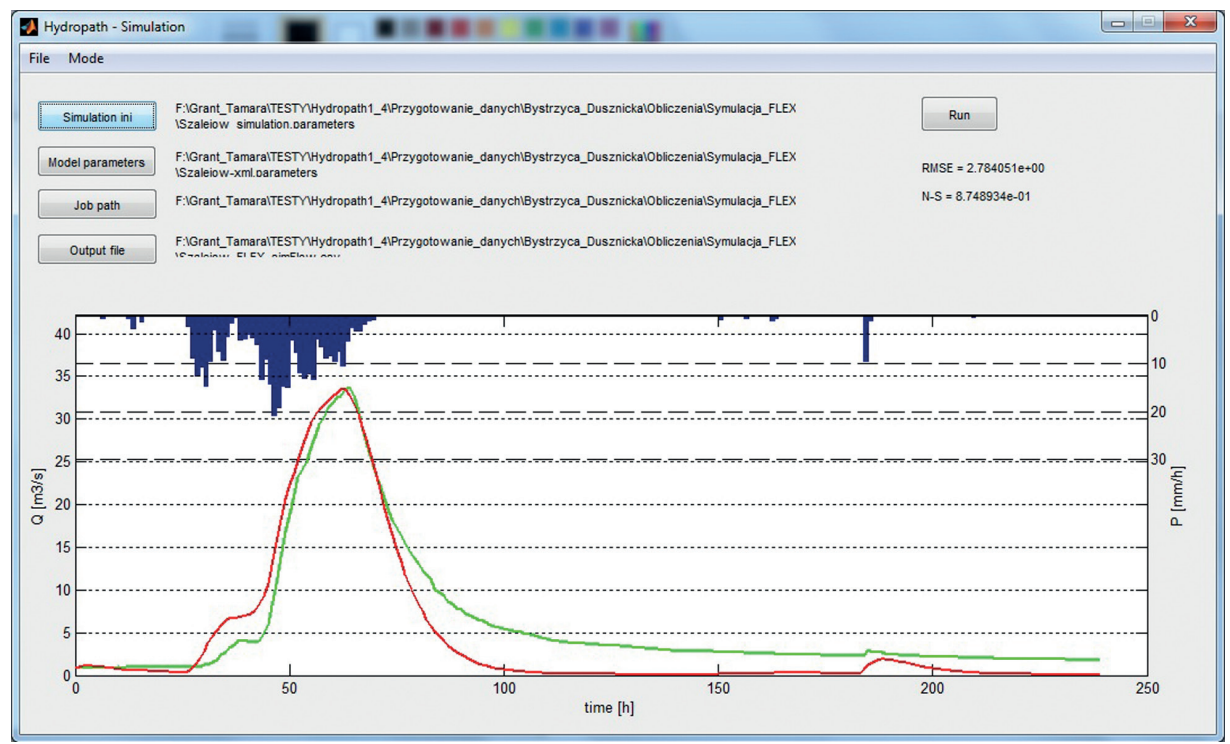

Fig. 8. Flood wave simulation with the use of TOPO-Flex model for Bystrzyca Dusznicka; green line - the observed hydrograph, red line - the simulated hydrograph for the period 20-30.07.2011 
computational environment began with the construction of the tools to build the relatively simple model structures (conceptual models with lumped parameters). Within the next cycles the development will include modules for deploying the structures of increasing complexity. In parallel, the development will concern the operability of the computational environment by adding different modes of operation: simulation, real-time, forecasting.

The computational environment components available at this stage of software development are responsible for the potential for producing the conceptual models either with lumped parameters or partially distributed. The formal description of the model structure takes the form of input data contained in XML format files from which - by way of parsing - a computational model is built that uses the prepared programming library. As part of the computational environment, the following were developed: an application programming interface (API), a module for the assimilation of external data and for binding the model with real object and the optimisation of the model parameters module.

The current stage of the development of HYDROPATH software allowed performance of selected basin schematisation, the building of a hydrological rainfall-runoff model for the catchment and the calibration of the adopted model. The HYDROPATH environment was used to prepare the test versions of TOPMODEL and TOPO-Flex. The constructed models were tested on selected catchments of the Nysa Kłodzka basin, including the Bystrzyca Dusznicka catchment.

The results obtained so far encourage further system development. In the next phase, further expansion of the computational environment is planned, with additional features, such as other methods of optimising the parameters, creating models of semi-distributed parameters, and the construction of a global model to be included. The developed computing environment will allow for the testing of different model structures and the diagnosis of the impact of model structure and spatial representation of the model parameters on the quality of simulation result runoff from catchments under different basin and weather conditions. This will allow for the performance of comparative analysis of the results obtained from various methods of calculation and the assessment of the uncertainty of the runoff forecasts.

\section{Bibliography}

Anderson M.P., Woessner W.W., 1992, Applied groundwater modeling: simulation of flow and advective transport, $2^{\text {nd }}$ ed., Academic Press, 381pp.
Bäck T., Schwefel H.P., 1993, An overview of evolutionary algorithms for parameter optimization, Evolutionary Computation, 1 (1), 1-23

Beven K.J., Lamb R., Quinn P.F., Romanowicz R., Freer J., 1995, TOPMODEL, [in:] Computer Models of Watershed Hydrology, V.P. Singh (eds.), Water Resources Publications, Colorado, USA, 627-668

Brown V.A., McDonnell J.J., Burns D.A., Kendall C., 1999, The role of event water, a rapid shallow flow component and catchment size in summer stormflow, Journal of Hydrology, 217 (3-4), 171-190, DOI: 10.1016/S0022-1694(98)00247-9

Butts M., Paynea J.T., Kristensen M., Madsena H., 2004, An evaluation of the impact of model structure on hydrological modelling uncertainty for streamflow simulation, Journal of Hydrology, 298 (1-4), 242-266, DOI: 10.1016/j.jhydrol.2004.03.042

Chormański J., Michałowski R., 2011, Hydrological catchment model WetSpa-SGGW integrated with a calculation module in ArcGIS environment (in Polish), Przegląd Naukowy Inżynieria i Kształtowanie Środowiska, 53, 196-206

Chou C.-M., 2012, Particle swarm optimization for identifying rainfall-runoff relationships, Journal of Water Resource and Protection, 2, 115-126, DOI: 10.4236/jwarp.2012.43014

Clark M.P., Kavetski D., Fenicia F., 2011, Pursuing the method of multiple working hypotheses for hydrological modelling, Water Resources Research, 47 (9), DOI: 10.1029/2010WR009827

Clark M.P., Slater A., Rupp D., Woods R., Vrugt J., Gupta H., Wagener T., Hay L.E., 2008, Framework for Understanding Structural Errors (FUSE): A modular framework to diagnose differences between hydrological models, Water Resources Research, 44 (12), 1-14, DOI: 10.1029/2007WR006735

Cloke H.L., Pappenberger F., 2009, Ensemble flood forecasting: a review, Journal of Hydrology, 375 (3-4), 613-626, DOI: 10.1016/j.jhydrol.2009.06.005

Fenicia F., Kavetski D., Savenije H.H.G., 2011, Elements of a flexible approach for conceptual hydrological modeling: 1. Motivation and theoretical development, Water Resources Research, 47 (11), DOI: 10.1029/2010WR010174

Fenicia F., McDonnell J.J., Savenije H.H.G., 2008a, Learning from model improvement: on the contribution of complementary data to process understanding, Water Resources Research, 44 (6), DOI: 10.1029/2007WR006386

Fenicia F., Savenije H.H.G., Pfister P.M.L., 2007, A comparison of alternative multiobjective calibration strategies for hydrological modelling, Water Resources Research, 43 (3), DOI: 10.1029/2006WR005098

Fenicia F., Savenije H.H.G., Pfister P.M.L., 2008b, Understanding catchment behavior through stepwise model concept improvement, Water Resources Research, 44 (1), DOI: 10.1029/2006WR005563 
Gan T.Y., Dlamini E.M., Biftu G.F., 1997, Effects of model complexity and structure, data quality, and objective functions on hydrologic modelling, Journal of Hydrology 192 (1-4), 81-103, DOI: 10.1016/S0022-1694(96)03114-9

Gao H., Hrachowitz M., Fenicia F., Gharari S., Savenije H.H.G., 2014, Testing the realism of a topography-driven model (FLEX-Topo) in the nested catchments of the Upper Heihe, China, Hydrology and Earth System Sciences, 18, 18951915, DOI: 10.5194/hess-18-1895-2014

Gądek W., 2002, Mathematical model of runoff from a watershed with spatially a decomposed calculation grid (in Polish), Zeszyty Naukowe Politechniki Krakowskiej - Seria Inżynieria Środowiska, 49, 134 pp.

Gharari S., Hrachowitz M., Fenicia F., Savenije H.H.G., 2011, Hydrological landscape classification: investigating the performance of HAND based landscape classifications in a central European mesoscale catchment, Hydrology and Earth Systems Science, 15, 3275-3291, DOI: 10.5194/hess-15-3275-2011

Gharari S., Hrachowitz M., Fenicia F., Gao H., Savenije H.H.G., 2014, Using expert knowledge to increase realism in environmental system models can dramatically reduce the need for calibration, Hydrology and Earth System Sciences, 18, 4839-4859, DOI: 10.5194/hess-18-4839-2014

Gupta H.V., Sorooshian S., Yapo P.O., 1998, Toward improved calibration of hydrologic models: multiple and noncommensurable measures of information, Water Resources Research, 34 (4), 751-763, DOI: 10.1029/97WR03495

Gupta H.V., Wagener T., Liu Y., 2008, Reconciling theory with observations: elements of a diagnostic approach to model evaluation, Hydrological Processes, 22, 3802-3813, DOI: 10.1002/hyp.6989

Georgakakos K.P., Seo D.-J., Gupta H., Schaake J., Butts M.B., 2004, Characterizing streamflow simulation uncertainty through multimodel ensembles, Journal of Hydrology, 298 (1-4), 222-241, DOI: 10.1016/j.jhydrol.2004.03.037

Hümann M., Müller C., 2013, Improving the GIS-DRP approach by means of delineating runoff characteristics with new discharge relevant parameters, ISPRS International Journal of Geo-Information, 2, 27-49, DOI: 10.3390/ijgi2010027

Kavetski D., Fenicia F., 2011, Elements of a flexible approach for conceptual hydrological modeling: 2. Application and experimental insights, Water Resources Research, 47 (11), DOI: 10.1029/2011WR010748

Kirchner J.W., 2006, Getting the right answers for the right reasons: linking measurements, analyses, and models to advance the science of hydrology, Water Resources Research, 42 (3), DOI: 10.1029/2005WR004362

Lastoria B., 2008, Hydrological processes on the land surface: a survey of modeling approaches, University of Trento, Italy, 60 pp., available at http://www.ing.unitn.it/dica/tools/download/Quaderni/Foralps_TR_9.pdf(data access 02.06.2016)
Müller C., Hellebrand H., Seeger M., Schobel S., 2009, Identification and regionalization of dominant runoff processes - a GISbased and a statistical approach, Hydrology and Earth System Sciences, 13, 779-792, DOI: 10.5194/hess-13-779-2009

Nash J.E., Sutcliffe J.V., 1970, River flow forecasting through conceptual models part I - A discussion of principles, Journal of Hydrology, 10 (3), 282-290, DOI: 10.1016/00221694(70)90255-6

Nocedal J., Wright S.J., 2006, Numerical Optimization, Springer Series in Operations Research and Financial Engineering, Springer-Verlag, New York, USA, 664 pp., DOI: 10.1007/9780-387-40065-5

Nobre A.D., Cuartas L.A., Hodnett M., Rennó C.D., Rodrigues G., Silveira A., Waterloo M., Saleska S., 2011, Height Above the Nearest Drainage - a hydrologically relevant new terrain model, Journal of Hydrology, 404 (1-2), 13-29, DOI: 10.1016/j.jhydrol.2011.03.051

Perrin C., Michel C., Andréassian V., 2001, Does a large number of parameters enhance model performance? Comparative assessment of common catchment model structures on 429 catchments, Journal of Hydrology, 242 (3-4), 275-301, DOI: 10.1016/S0022-1694(00)00393-0

Press W.H., Teukolsky S.A., Vetterling W.T., Flannery B.P., 2007, Numerical recipes. The art of scientific computing, $3^{\text {rd }}$ edition, Cambridge University Press, 1256 pp.

Pushpalatha R., Perrin C., Le Moine N., Mathevet T., Andréassian V., 2011, A downward structural sensitivity analysis of hydrological models to improve low-flow simulation, Journal of Hydrology, 411 (1-2), 66-76, DOI: 10.1016/j.jhydrol.2011.09.034

Rennó C.D., Nobre A.D., Cuartas L.A., Soares J.V., Hodnett M.G., Tomasella J., Waterloo M.J., 2008, HAND, a new terrain descriptor using SRTM-DEM: Mapping terra-firme rainforest environments in Amazonia, Remote Sensing of Environment, 112 (9), 3469-3481, DOI: 10.1016/j.rse.2008.03.018

Romanowicz R.J., 1997, A MATLAB implementation of TOPMODEL, Hydrological Processes, 11 (9), 1115-1129, DOI: 10.1002/(SICI)1099-1085(199707)11:9<1115::AID-HYP $548>3.0 . \mathrm{CO} ; 2-\mathrm{T}$

Savenije H.H.G., 2010, HESS Opinions "Topography driven conceptual modeling (FLEX-Topo)", Hydrology and Earth System Sciences, 14, 2681-2692, DOI: 10.5194/hess-142681-2010

Shamir E., Imam B., Morin E., Gupta H.V., Sorooshian S., 2005, The role of hydrograph indices in parameter estimation of rainfall-runoff models, Hydrological Processes, 19, 2187 2207, DOI: 10.1002/hyp.5676

Seiller G., Anctil F., Perrin C., 2012, Multimodel evaluation of twenty lumped hydrological models under contrasted climate conditions, Hydrology and Earth System Sciences, 16 (4), 1171-1189, DOI: 10.5194/hess-16-1171-2012 
Soczyńska U., 1997, Dynamic Hydrology (in Polish), Wydawnictwo Naukowe PWN, Warszawa, 409 pp.

Szalińska W., Tokarczyk T., Chorążyczewski A., Jełowicki J., Michalski A., Tiukało A., Ostojski M.S., 2014, Computational environment of the operational rainfall-runoff model (in Polish), [in:] Monografie Komitetu Gospodarki Wodnej PAN, Hydrologia w inżynierii i gospodarce wodnej, K. Banasik, L. Hejduk, E. Kaznowska (eds.), 293-306

Son K., Sivapalan M., 2007, Improving model structure and reducing parameter uncertainty in conceptual water balance models through the use of auxiliary data, Water Resources Research, 43 (1), DOI: 10.1029/2006WR005032

Szturc J., Jurczyk A., Ośródka K., Struzik P., Otop I., 2014, Estimation of the surface rainfall field with the use of different data sources together with the spatial information on their quality (in Polish), [in:] Monografie Komitetu Gospodarki Wodnej PAN, Hydrologia w ochronie i kształtowaniu środowiska, A. Magnuszewski (ed.), 19-30

Todini E., 2006, Rainfall-runoff models for real-time forecasting, [in:] Encyclopedia of Hydrological Sciences, John Wiley \& Sons, 11-123, DOI:10.1002/0470848944.hsa131.

Thyer M., Renard B., Kavetski D., Kuczera G., Franks S.W., Srikanthan S., 2009, Critical evaluation of parameter consistency and predictive uncertainty in hydrological modeling: a case study using Bayesian total error analysis, Water Resources Research, 45 (12), DOI: 10.1029/2008WR006825

Vaze J., Post D.A., Chiew F.H.S., Perraud J.-M., Teng J., Viney N.R., 2011, Conceptual rainfall-runoff model performance with different spatial rainfall inputs, Journal of Hydrometeorology, 12 (5), 1100-1112, DOI: 10.1175/2011JHM1340.1

Velazquez J.A., Anctil F., Ramos M.H., Perrin C., 2011, Can a multi-model approach improve hydrological ensemble forecasting? A study on 29 French catchments using 16 hydrological model structures, Advances in Geosciences, 29, 33-42, DOI: 10.5194/adgeo-29-33-2011

Wagener T., Boyle D.P., Lees M.J., Wheater H.S., Gupta H.V., Sorooshian S., 2001, A framework for development and application of hydrological models, Hydrology and Earth System Sciences, 5 (1), 13-26, DOI: 10.5194/hess-5-13-2001

Wagener T., McIntyre N., 2005, Identification of rainfall-runoff models for operational applications, Hydrological Sciences Journal, 50 (5), 735-751, DOI: 10.1623/hysj.2005.50.5.735

Wagener T., McIntyre N., Lees M.J., Wheater H.S., Gupta H.V., 2003, Towards reduced uncertainty in conceptual rainfallrunoff modeling: Dynamic identifiability analysis, Hydrological Processes, 17 (2), 455-476, DOI: 10.1002/hyp.1135

Westerberg I.K., Guerrero J.-L., Younger P.M., Beven K.J., Seibert J., Halldin S., Freer J.E. Xu C.-Y., 2011, Calibration of hydrological models using flow-duration curves, Hydrology and Earth System Sciences, 15, 2205-2227, DOI: 10.5194/ hess-15-2205-2011

Yilmaz K.K., Gupta H.V., Wagener T., 2008, A process-based diagnostic approach to model evaluation: application to the NWS distributed hydrologic model, Water Resources Research, 44 (9), DOI: 10.1029/2007WR006716 